emphasized. Visits, lectures and films, such as instructional films on new machinery, were used in addition to background reading material to ensure that translators were familiar with the subjects of the papers they had to translate. Only the highest quality of written translation was produced but, for speed, when only one inquirer wished for a translation, the peper could be very satisfactorily examined orally by the translator and the subject specialist. The concept of a 'rough translation' as something cheaper and easier to make than proper translation was based on a misunderstanding of the translation process which was to understand first, and then to re-express in English. Many papers could be clearer in a well-expressed translation, but those papers which were obscure, because they were ill-written and ambiguous even to a specialist, imposed an intolerable burden on the translator.

In discussion, Dr. D. J. Urquhart (Department of Scientific and Industrial Research) supported an organized system of cover-to-cover translation as the only real answer to the situation, together with the widest possible use of English by scientific journals. There was general agreement with this and with the proposition that students should be trained in foreign languages, particularly Russian, if only to employ translators more effectively. It was recommended that those translating papers should notify the Aslib index when they begin a translation so that duplication might be avoided. Many enthusiasts spoke on various aspects of translation without expressing views which diverged seriously from those of the main speakers, except that many preferred that scientists should be trained in languages rather than that linguists should be taught technology.

It was resolved, on the initiative of Dr. Urquhart, that Aslib should be recommended to convene a further conference "to see what measures can be taken to make Russian scientific and technical literature available in English". The meeting also passed a resolution from Dr. Clason (Philips, Eindhoven) that the whole question of translation required fuller consideration by a three-day conference. Discussion was terminated with a resolution that the Unesco Report proposals, circulated with the conference documents, should be sent out to participants as a questionnaire, so that the opportunity of obtaining the opinions of those attending the conference should not be lost through lack of time. The papers and discussion will be published later in "Aslib Proceedings". $\quad$ A. L. MACKAY

\title{
HIGH POLYMERS
}

T HE Kelvin Lecture, delivered on February 6 to the Institution of Electricel Engineers by Sir Harry Melville, dealt with the chemical structure and physical behaviour of high polymers. After giving an account of the underlying principles, Sir Harry dealt with natural and artificial rubber, polyethylene, synthetic fibres and ion-exchange fibres. The lecture brought out very well the co-ordination of chemistry, physics and engineering in the field of high polymers, and showed to what a large extent materials of this kind are finding all kinds of uses, and how their properties may to some extent be controlled on the basis of theory.

The fundamental property of a high polymeric material is its high molecular weight, which may increase from upwards of 10,000 to values of the order of a million for linear molecules and indefinitely large values for non-linear systems. The molecules should consist of long chains of atoms to which sidechains are attached. The groups in these side-chains may be able to rotate freely or may be joined by cross-links. If the main chain contains double bonds, its members will be hindered from rotation. If the number of molecules in the chain is not very large, the chain may coil into a spherical shape, and rubber is normally in this form. In stretching the rubber, the chains uncoil under moderate tension. Unvulcanized rubber behaves differently and tends to orystallize on extension. Vulcanization puts in crosslinks, which are not extensive enough to prevent uncoiling. In synthetic rubbers the aim is to produce chains not long enough to form crystallites, and a recent discovery by the British Rubber Producers Reserch Association consists in modifying the chemical composition so that the chains cannot form such crystallites.

Silicones have chains of silicon and oxygen atoms in repeating units with various groups attached to the silicon atoms. They vary from mobile liquids, the viscosity of which is only very little affected by temperature, to rubber-like solids.

Polyethylene is a linear chain of carbon atoms with hydrogen atoms attached when the polymerization is carried out at room temperature. At higher temperatures and high pressures the molecules have many branches attached to the linear chain, and this has an important effect on the properties. By exposure to high-energy radiation such as gammaradiation, hydrogen atoms are removed from the chains, leaving free radicals, which join to give crosslinks, forming a three-dimensional structure which at high enough temperatures decomposes rather than melts.

Synthetic fibres must have a high tensile strength. It is curious that among the strongest natural and synthetic fibres the tensile strength does not vary much. The strength is much less than that caleulated for breaking the chemical bonds, and it is less than the calculated value for other plausible struotures, so that no explanation is yet known. The modulus of elasticity is close to the calculated value. The lecture dealt with the changes produced by altering the chemical composition. Fibres and rubber are closely related and relatively small changes in chemical structure influence their properties quite markedly.

Ion-exchange fibres are made by mixing highpolymer molecules containing carboxyl or acid groups and hydroxyl or alcohol groups, and heat treatment. They are in effect solid acids. In an acid liquid the fibre swells. If the acid is replaced by an alkali the molecules stretch, but if the fibre is put into acid its original state is restored. Theoretically, mechanical energy could be derived from such a system, but at present the efficiency is very low. 